\title{
Allelopathic activity of Elodea canadensis and Elodea nuttallii against epiphytes and phytoplankton
}

\author{
Daniela Erhard*, Elisabeth M. Gross \\ Limnological Institute, University of Konstanz, Box M 659, D-78457 Konstanz, Germany \\ Received 30 September 2005; received in revised form 17 March 2006; accepted 10 April 2006
}

\begin{abstract}
Elodea nuttallii and Elodea canadensis have both been introduced from North America to Europe. They are now common in many water bodies where they often form dominating stands. It was suggested that negative relationships between Elodea and phytoplankton or epiphytic covers exist, probably due to the release of growth inhibiting allelochemicals. This would be an effective strategy to avoid light limitation caused by algae and cyanobacteria. We investigated the allelopathic potential of both E. nuttallii and E. canadensis against different photoautotrophs, focussing on epiphytic algae and cyanobacteria isolated from different submersed macrophytes and culture strains. Methanolic extracts of both species inhibited the growth of most of these organisms. Only a culture strain of Scenedesmus brevispina was stimulated. Further separation of extracts yielded several active fractions, indicating that hydrophilic and slightly lipophilic compounds were responsible for growth reduction. At least some of the activity seems to be related to phenolic substances, but flavonoids in these species are inactive. Since growth declined also in a moderately lipophilic fraction of culture filtrate of $E$. nuttallii, we assume that active compounds were exuded in the water. Allelopathy might thus be relevant in situ and suppress cyanobacteria and algae. We furthermore found differences in the susceptibility of target organisms, which could (1) at least partly be a result of adaptation to the respective host plants and (2) indicate that allelopathic interference might reduce the abundance of some species, especially cyanobacteria, in epiphytic biofilms.
\end{abstract}

Keywords: Allelopathy; Epiphytes; Invasive species; Phytoplankton; Submersed macrophyte

\section{Introduction}

Elodea canadensis and Elodea nuttallii were introduced to Europe in 1836 and 1939, respectively, and since then are actively spreading over the continent. Both species reached and still reach high densities, often forming monospecific stands and probably displacing native vegetation (Thiebaut et al., 1997; Barrat-Segretain, 2001; Tremp, 2001). Competitive exclusion of other macrophytes has so far been considered the major factor in this process. Elodea spp. inhabit meso- to eutrophic waters and exhibit high growth rates under a broad range of environmental conditions and nutrient concentrations. With light compensation points of 12 and $33 \mu \mathrm{mol} \mathrm{m}^{-2} \mathrm{~s}^{-1}$ (for E. canadensis and E. nuttallii, respectively), they are adapted to low light intensities but also tolerate intensities of up to

\footnotetext{
* Corresponding author. Tel.: +49 753188 3112; fax: +49 7531884136. E-mail addresses: Daniela.Erhard@uni-konstanz.de (D. Erhard), Elisabeth.Gross@uni-konstanz.de (E.M. Gross).
}

$1100 \mu \mathrm{mol} \mathrm{m}{ }^{-2} \mathrm{~s}^{-1}$ without symptoms of photoinhibition (Jahnke et al., 1991; Madsen et al., 1991). This allows them to grow in shallow waters as well as to maximum depths of 13 m (Vöge, 1994; Schmieder, 1998).

Recent studies show that allelopathic interactions might contribute more to the success of invasive plant species than previously thought (Bais et al., 2003; Fitter, 2003). For rooted submersed macrophytes, although generally adapted to low light conditions, allelopathy might be an effective strategy to prevent light limitation due to shading by phytoplankton or epiphytes. Both can further reduce the inherently poor light conditions under water (Phillips et al., 1978; Sand-Jensen and Søndergaard, 1981) and lead to a decline of aquatic vegetation (Jupp and Spence, 1977). Allelopathy has been described for many aquatic angiosperms (summarised in, e.g., Gopal and Goel, 1993; Gross, 2003), among them Myriophyllum spicatum, which is invasive in North America. Previous observations already indicated a negative relationship between Elodea and algae or cyanobacteria. Hasler and Jones (1949) reported lower phytoplankton densities in the presence of 
E. canadensis, and both E. canadensis and E. nuttallii were less covered with epiphytes than other submersed macrophytes (Wium-Andersen, 1987; Jones et al., 1999; Gross et al., 2003b). Our research revealed that Elodea might be chemically defended against insect herbivores (Erhard, unpublished results), and waterweeds may also produce secondary metabolites that inhibit the growth of co-occurring primary producers. However, allelopathic interactions of Elodea with aquatic primary producers have only seldom been investigated and never considered as factor for their successful spread and establishment in so many lakes. One study investigating the allelopathic activity of $E$. nuttallii extracts demonstrated an inhibitory effect on seedlings of lettuce and other terrestrial plants (El-Ghazal and Riemer, 1986). From an ecological point of view, the use of such indicator organisms is questionable. Wium-Andersen (1987) found inhibitory effects of $E$. canadensis on photosynthesis of the diatom Nitzschia, but such effects were not observed with $E$. nuttallii (Leu, 2001).

The aim of the present study was to examine the potential allelopathic activity of two Elodea species, E. canadensis and E. nuttallii, against epiphytic algae and cyanobacteria. We extracted and fractionated active compounds from plant tissue to gain more information on their chemical properties. We also investigated the release of allelochemicals by Elodea to show whether allelopathy might be effective in natural ecosystems.

\section{Materials and methods}

\subsection{Macrophytes}

Elodea nuttallii and E. canadensis originated from different locations. Plant samples of E. nuttallii were taken from Lower Lake Constance, from a small pond at the campus of the University of Konstanz (both Southern Germany), from Harkortsee (Western Germany, lyophilised plants provided by E.A. Nusch, Ruhrverband, Essen, Germany), or from a laboratory aquarium culture $\left(16^{\circ} \mathrm{C}, 50 \mu \mathrm{mol} \mathrm{m}^{-2} \mathrm{~s}^{-1}, \mathrm{~L}: \mathrm{D}\right.$ 14:10) of the pond specimens. E. canadensis was obtained from the botanical garden of the University of Marburg (Germany), from Lake Rotcze (Poland, dried material provided by R.
Kornijow, University of Lublin), and from Lower Lake Constance. Material was kept separately based on location and sampling time. Fresh plants were rinsed free of debris, frozen in liquid nitrogen, and freeze-dried. Lyophilised material was finely ground and stored air-tight at room temperature in the dark until use.

\subsection{Algae and cyanobacteria}

We used several different strains of indicator organisms in our bioassays (Table 1). Epiphytic isolates were obtained by plating shoot sections of different macrophytes on agar containing cyanobacteria medium. This medium supports the growth of cyanobacteria and chlorophytes but not of diatoms because no silica is added. Those strains that were isolated from the surface of submersed macrophytes were regarded as "epiphytic", while the commercially available cultures were regarded as "planktonic" based on information available on these strains. This does not mean that those species solely occur in the respective habitats. All organisms were kept as liquid batch cultures in cyanobacteria medium modified after Jüttner et al. (1983), with $150 \mathrm{mg} \mathrm{l}^{-1}$ TES as buffer. The cultures were placed on an orbital shaker $(115 \mathrm{rpm})$ and incubated at $22 \pm 1{ }^{\circ} \mathrm{C}, 70 \mu \mathrm{mol} \mathrm{m}{ }^{-2} \mathrm{~s}^{-1}$, and a photoperiod of L:D 13:11.

\subsection{Crude extracts of Elodea}

Plant material was extracted twice for $2 \mathrm{~h}$ in $50 \%(\mathrm{v} / \mathrm{v})$ aqueous methanol (Gross et al., 2003a). Aliquots of these extracts were evaporated to dryness and resuspended in 50\% methanol to a final concentration of $100 \mathrm{mg}$ plant dry weight (DW) per milliliter. Controls using only solvent without plant material were prepared in the same way.

\subsection{Fractionation of crude extracts}

Crude extracts of Elodea and control extracts were further separated by solid phase extraction (SPE) to isolate allelopathically active fractions. Aliquots of extracts were diluted with ultrapure water to a final concentration of $2.5 \%$ methanol.

Table 1

Cyanobacterial and algal strains used as target organisms in our bioassay systems

\begin{tabular}{llll}
\hline Species & Strain & Axenic & Notes \\
\hline Cyanobacteria & & & Long-term culture at the institute \\
Anabaena sp. & PCC 7120 & Yes & Long-term culture at the institute \\
Anabaena variabilis P9 & ATCC 29413 & Yes & Long-term culture at the institute \\
Synechococcus elongatus & SAG 89.79 & No & Isolated from Myriophyllum spicatum \\
Pseudanabaena cf. catenata & Myr 9807 & No & Isolated from Chara sp. \\
Synechococcus sp. & Cha 9817 & No & Isolated from Potamogeton pectinatus \\
Synechococcus nidulans & Pot 9801 & No & Isolated from Najas marina ssp. intermedia \\
Green algae & & & Isolated from Elodea nuttallii \\
Scenedesmus brevispina & Naj S52 & No & No \\
Chlorella cf. vulgaris & Elo 5B & &
\end{tabular}

ATCC: American Type Culture Collection, Manassas, VA, USA; PCC: Pasteur Culture Collection, Paris, France; SAG: Sammlung von Algenkulturen, Göttingen, Germany. The cyanobacterial epiphytic strains from different submersed macrophytes were isolated by C. Postius, the epiphytic green algae by E. Ivanyi, both at the University of Konstanz. 
They were then passed over a preconditioned SPE-C18 cartridge (Varian Bond Elut, $12 \mathrm{ml}, 2 \mathrm{~g}$ sorbens) with a flow rate of $3 \mathrm{ml} \mathrm{min}^{-1}$. The cartridge was washed with $10 \mathrm{ml}$ of $2.5 \%$ methanol and then stepwise eluted with each $10 \mathrm{ml}$ of 10 $100 \%$ methanol (increasing at 10\% intervals). This yielded 11 fractions in total. All fractions were evaporated to dryness and resuspended in $50 \%$ methanol to a final concentration of $100 \mathrm{mg} \mathrm{DW} \mathrm{ml}{ }^{-1}$.

\subsection{Precipitation of phenolic compounds}

To test whether phenolic substances exhibited allelopathic activity, we mixed aqueous aliquots of extracts and fractions (pH adjusted with $\mathrm{HCl}$ to $\leq 5$, if necessary) with insoluble PVPP (Sigma P-6755, final concentration 5\% [w/v]) to precipitate phenolic compounds (Loomis and Battaile, 1966). After incubation over night at $8{ }^{\circ} \mathrm{C}$, suspensions were centrifuged, supernatants evaporated to dryness and resuspended in $50 \%$ methanol.

\subsection{Flavonoids from Elodea}

Elodea canadensis and E. nuttallii contain 7-O-diglucuronides of the flavones luteolin, apigenin and chrysoeriol (Mues, 1983). To assess the importance of these compounds for allelopathic activity, we tested purified flavonoid fractions in our bioassay systems. Flavonoid samples were isolated by preparative reversed phase chromatography (modified after Erhard and Gross, 2005), and provided by G. Pohnert, MPI for Chemical Ecology, Jena. The luteolin derivative was isolated as single compound, whereas the apigenin and chrysoeriol derivatives could not be separated, and thus were always applied together. Luteolin-7-O-diglucuronide was used in amounts of 5-20 $\mu \mathrm{g}$ per test, equivalent to its content usually found in $1-2 \mathrm{mg}$ plant DW. The two other flavonoids were applied in amounts of up to $6 \mu \mathrm{g}$ per test (both substances together).

\subsection{Exudation of allelochemicals}

We examined whether active compounds were also exuded by live plants into the surrounding medium. Due to the lack of live $E$. canadensis, the experiment was conducted only with $E$. nuttallii. Fresh rootless upper shoots $(25 \mathrm{~cm})$ without obvious damage to leaves or side shoots were cut from longer shoots, tied into bunches with parafilm and submersed in tap water for

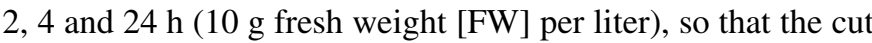
shoot ends were sealed with parafilm and did not have contact with the water. At the same time, controls were performed under the same conditions but with tap water only. This experiment was triplicated with different plant material. In experiment 3, only four and $24 \mathrm{~h}$ were tested. The incubation water was subsequently filtered over filter paper (MN 615, Macherey-Nagel, Düren, Germany) and membrane filters with $0.2 \mu \mathrm{m}$ pore size (OE 66, Schleicher \& Schuell, Dassel, Germany), and then passed over preconditioned C18 filter disks (3 M Empore ${ }^{\mathrm{TM}}$ High Performance Extraction Disks, $47 \mathrm{~mm}$ $\varnothing, 3$ M, St. Paul, MN, USA). The filter was washed with a small volume of ultrapure water and vacuum dried for $1 \mathrm{~min}$. Adsorbed compounds were eluted three times with $10 \mathrm{ml}$ of methanol according to the instructions by the manufacturer. Both aqueous eluent and methanolic eluate were evaporated to dryness and redissolved in 50\% methanol.

\subsection{Bioassays}

We used two different assays to investigate the allelopathic activity of extracted compounds. In the agar diffusion assay (ADA, Gross et al., 2003a), we screened them against the filamentous cyanobacteria, Anabaena spp. Extracts (equivalent to $0.5-2 \mathrm{mg} \mathrm{DW}$ ), fractions (equivalent to $2 \mathrm{mg} \mathrm{DW}$ ) or purified compounds (2-20 $\mu \mathrm{g})$ and equivalent solvent controls were spotted on an agar plate and dried in a sterile stream of air. Cyanobacteria were inoculated at optical densities (measured at $530 \mathrm{~nm} ; \mathrm{OD}_{530}$ ) of $0.04 \mathrm{AU}$ (absorption units) in cyanobacteria medium containing $1 \%$ agar. This overlayer agar was poured on the prepared agar plates which were, after gelling of the overlayer, incubated for 7 days at $28{ }^{\circ} \mathrm{C}$ and constant illumination $\left(80 \mu \mathrm{mol} \mathrm{m}{ }^{-2} \mathrm{~s}^{-1}\right)$. Growth inhibiting extracts caused clearing zones in the overlayer agar containing the target organisms, and in general, the size of these zones increased with the amount of extract applied. However, the ADA allows only a semi-quantitative interpretation, and furthermore turned out to be less suitable for coccal and epiphytic test organisms. We thus tested plant extracts and fractions against all strains except Anabaena spp. in liquid cyanobacteria medium. This liquid culture assay (LCA) was adapted from Schrader et al. (1997) and conducted in sterile 24-well plates. Extracts and fractions were applied to the wells and dried under a sterile air stream. Two millilitres of test organism culture $\left(\mathrm{OD}_{530}=0.04 \mathrm{AU}\right)$ were then filled in each well, so that final extract concentrations ranged from 0 to $1 \mathrm{mg} \mathrm{DW} \mathrm{ml}{ }^{-1}$. When tested against the green algae, extract concentrations up to $4 \mathrm{mg} \mathrm{DW} \mathrm{ml}^{-1}$ were used. Wells containing only medium without organisms were prepared to correct for absorption caused by extracts. Plates with control extracts and fractions were performed in the same way, and all assays were run in triplicate. After incubation for seven days (see conditions for agar diffusion assay), the $\mathrm{OD}_{530}$ was measured again, and growth of treated cultures was set in relation to that of control cultures. This method allowed us to determine the concentration of Elodea extract necessary to cause a $50 \%$ growth inhibition compared to the controls $\left(\mathrm{IC}_{50}\right) . \mathrm{IC}_{50}$ were calculated from $\mathrm{EC}_{50}$ values computed in SigmaPlot 9.0 using the sigmoid dose-response model with variable slope.

\subsection{Statistical analysis}

All data were analysed by parametric tests (i.e. Student's $t$-test or ANOVA) when data were normally (KolmogorovSmirnov test, $\alpha=0.05$ ) and variances homogenously $\left(F_{\max }\right.$ test, $\alpha=0.05$ ) distributed. In most cases, transformations were necessary to remove heteroscedasticy. If transformations 
failed to correct for this, the significance level for ANOVAs was lowered to 0.01 where usually $\alpha=0.05$ is used. Tukey HSD or unequal $N$ HSD post-hoc tests were applied when ANOVAs revealed significant effects. The exudation experiment with $S$. elongatus was analysed by a Dunnett test. For the analysis of data from the LCA with untreated and PVPP treated fractions, two different data sets had to be used to examine differences to the controls and differences between treatments. We originally performed factorial ANOVAs with the $\mathrm{OD}_{530}$ values to compare the growth of test organisms with the controls and among treatments. However, in some cases even the control cultures differed among treatments (i.e. with and without PVPP). Thus, we used the relative growth values (percentage of control) to compare the effects of untreated and PVPP precipitated extracts and fractions. When transformation failed to correct for absence of normality or equal variances, we performed non-parametric tests (i.e. MannWhitney $U$ tests). All analyses were made with Statistica 6.0 (StatSoft Inc., Tulsa, USA) or JMP IN 5.1 (SAS Institute).

\section{Results}

\subsection{Allelopathic activity of Elodea crude extracts}

E. canadensis and E. nuttallii crude extracts caused clearing zones in the agar diffusion assay (ADA) with Anabaena sp. PCC 7120 and Anabaena variabilis P9 when 0.5-2 mg DW biomass equivalents were applied per spot (Table 2), while control extracts never inhibited the growth of target organisms. All plants, field as well as aquarium material, were active, but the size of clearing zones varied markedly between independent assays (e.g., E. nuttallii from Lake Constance or E. canadensis, botanical garden Marburg). The ADA provides only semiquantitative results due to differences in the diffusion of extracts in the agar. A direct comparison between experiments performed at different times is thus problematic. For quantitative analyses the LCA is more suitable. However, when E. nuttallii and E. canadensis were tested in the same assay, there was in general no difference between the two species. Only once, E. canadensis from Lake Constance caused larger clearing zones than E. nuttallii from the campus pond when applied to $A$. variabilis $\mathrm{P} 9$ at 0.5 and $1 \mathrm{mg}$ DW (MannWhitney $U$ test, $P=0.006$ and $P=0.011$; Table 2).

Assays with liquid cultures of different target organisms yielded similar results. Both Elodea species were active and inhibited the growth of all organisms except $S$. brevispina Naj S52 by at least $50 \%$. Most organisms were susceptible to concentrations less than $1 \mathrm{mg} \mathrm{DW} \mathrm{ml}^{-1}$, and at the highest concentration tested ( $1 \mathrm{mg} \mathrm{DW} \mathrm{ml}^{-1}$ ), crude extracts reduced growth of Synechococcus elongatus and the epiphytic cyanobacteria Pseudanabaena Myr 9807, Synechococcus sp. Cha 9817 and S. nidulans Pot 9801 on average by 56-92\% of the control cultures. Higher concentrations were necessary to cause a $50 \%$ inhibition of Chlorella Elo $5 \mathrm{~B}$, and the $\mathrm{IC}_{50}$ for all susceptible strains ranged from 0.2 to more than $4 \mathrm{mg} \mathrm{DW} \mathrm{ml}^{-1}$ (Fig. 1). A two-way ANOVA of $\mathrm{IC}_{50}$ values revealed significant differences between test organisms ( $F=11.009, P<0.001)$, but not between different Elodea species $(F=1.214, P=0.284)$. Chlorella cf. vulgaris Elo $5 \mathrm{~B}$, isolated from $E$. nuttallii, was less sensitive than the other organisms with the exception of the Potamogeton epiphyte $S$. nidulans Pot 9801 (unequal $N$ HSD, $P<0.05$ ), exhibiting an $\mathrm{IC}_{50}$ in different tests between 1 and more than $4 \mathrm{mg} \mathrm{DW} \mathrm{ml}^{-1}$. Growth of S. brevispina Naj S52 was either not influenced or even stimulated at concentrations up to $1 \mathrm{mg} \mathrm{DW} \mathrm{ml}^{-1}$ (Fig. 1). This was also observed at higher concentrations up to $4 \mathrm{mg} \mathrm{DW} \mathrm{ml}{ }^{-1}$ and thus, no $\mathrm{IC}_{50}$ could be determined.

\subsection{Fractionation of extracts}

Solid phase extraction of methanolic crude extracts yielded several active fractions. Three fractions of $E$. nuttallii extract were inhibitory in the ADA (Fig. 2). Fraction 1 (i.e. the unretained eluent) as well as fractions 10 and 11 (eluted with 90 and $100 \%$ methanol) reduced growth of Anabaena P9, but only fraction 10 caused perfect clearing zones in the overlayer. The other fractions led only to weak inhibition, i.e. some cyanobacteria still grew, causing weak clearing areas. In contrast to E. nuttallii, the unretained eluent of E. canadensis crude extract did not cause growth inhibition in the ADA (Fig. 2). Here, fractions 9 and 10 were most active against Anabaena P9 and resulted in clearing zones, and fraction 11

Table 2

Diameter (mm) of clearing zones caused by crude extracts of Elodea canadensis and Elodea nuttallii in the ADA

\begin{tabular}{|c|c|c|c|c|c|c|c|c|}
\hline \multirow[t]{2}{*}{ Organism } & \multirow[t]{2}{*}{ Plant DW (mg) } & \multicolumn{4}{|l|}{ E. nuttallii } & \multicolumn{3}{|l|}{ E. canadensis } \\
\hline & & Harkortsee & Lake Constance & Campus pond & Aquarium & Lake Rotcze & Botanical garden, Marburg & Lake Constance \\
\hline \multirow[t]{3}{*}{ PCC 7120} & 0.5 & $4.6 \pm 0.5$ & $\begin{array}{l}6.0 \pm 1.0 \\
(9.7 \pm 2.2)\end{array}$ & 0 & $3.7 \pm 0.7$ & $9.4 \pm 1.1$ & $\begin{array}{l}6.8 \pm 0.9 \\
(8.8 \pm 2.3)\end{array}$ & {$[+]$} \\
\hline & 1 & $8.1 \pm 1.1$ & $\begin{array}{l}9.4 \pm 0.9 \\
(11.5 \pm 1.7)\end{array}$ & + & $6.9 \pm 0.6$ & $12.5 \pm 1.2$ & $\begin{array}{l}10 \pm 0.7 \\
(11.6 \pm 2.6)\end{array}$ & + \\
\hline & 2 & $9.3 \pm 0.4$ & $\begin{array}{l}12.0 \pm 1.6 \\
(15.5 \pm 1.2)\end{array}$ & $6.2 \pm 1.1$ & $8.8 \pm 0.9$ & $13.6 \pm 1.2$ & $\begin{array}{l}12.3 \pm 1.2 \\
(14.4 \pm 2.3)\end{array}$ & $7.7 \pm 0.4$ \\
\hline \multirow[t]{3}{*}{ P9 } & 0.5 & - & - & $3.0 \pm 2.0$ & - & - & - & $5.0 \pm 0.0$ \\
\hline & 1 & - & - & $5.8 \pm 2.9$ & - & - & - & $8.1 \pm 0.7$ \\
\hline & 2 & - & - & $8.4 \pm 1.5$ & - & - & - & $8.9 \pm 0.5$ \\
\hline
\end{tabular}

Plants derived from different sampling sites in the field and from the aquarium. Given are means \pm S.D. $(N=5$ per experiment). [+]: weak inhibition in only few replicates, +: weak inhibition, -: not tested. Values in parentheses are from another extract of the respective plant sample. 
E. canadensis

O E. nuttallii

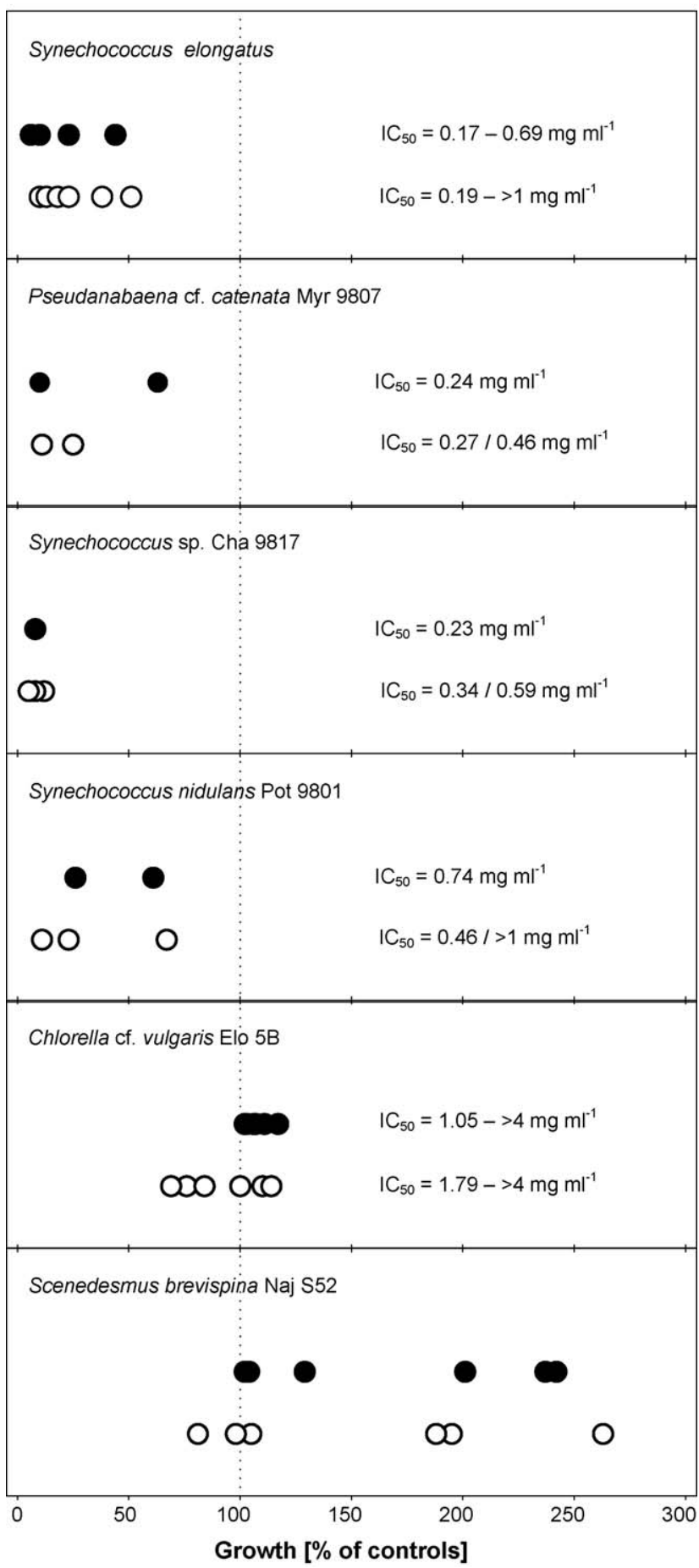

Fig. 1. Growth of different indicator organisms (percentage of control cultures) in the presence of $1 \mathrm{mg} \mathrm{DW} \mathrm{ml}{ }^{-1}$ crude extract from E. canadensis and $E$. nuttallii. Data show results from $N=2-6$ independent growth assays. The dotted line marks the growth of control cultures (i.e. 100\%). $\mathrm{IC}_{50}$ values represent the concentrations of extract necessary to reduce growth of organisms to $50 \%$ of the control cultures. Scenedesmus brevispina was not inhibited and thus, no $\mathrm{IC}_{50}$ could be calculated.

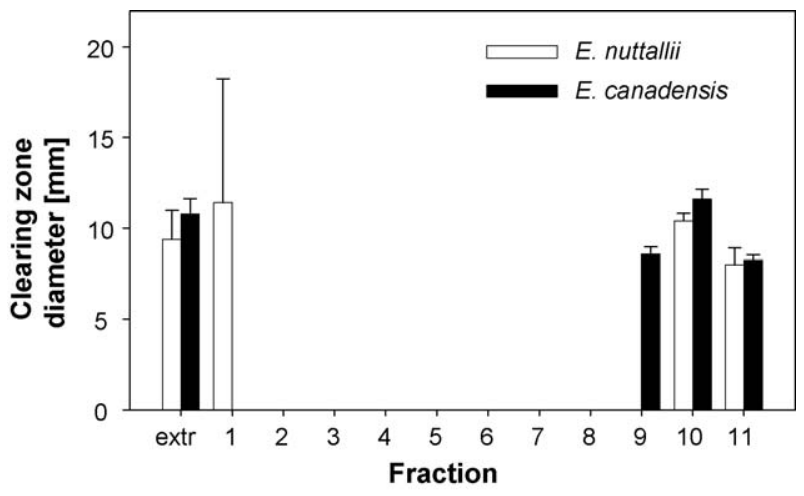

Fig. 2. Inhibition of Anabaena variabilis P9 by crude extract (extr) and SPE fractions (1-11) of E. canadensis and E. nuttallii in the ADA. Extracts and fractions were applied equivalent to $2 \mathrm{mg}$ DW. Bars represent diameters $(\mathrm{mm})$ of clearing zones (mean + S.D., $N=5$ ).

showed a weak inhibition. Solvent controls did not cause any inhibition in the ADA.

In the LCA, the different organisms tested were inhibited by crude extracts and selected fractions of both Elodea species (Fig. 3). Inhibitory effects against Synechococcus elongatus were apparent, but could not be verified by statistical analysis due to lack of normal distribution and equal variance. However, PVPP treatment significantly reduced the activity of E. nuttallii crude extract (Fig. 3A). Pseudanabaena cf. catenata Myr 9807 (Fig. 3B, F) was inhibited by fraction 10 of E. nuttallii and fractions 8,10 and 11 of $E$. canadensis. The inhibitory activity of fraction 11 remained after PVPP precipitation, while the activity of the other fractions was removed. Synechococcus sp. Cha 9817 was inhibited by fraction 10 of E. nuttallii and fractions 10 and 11 of $E$. canadensis. After PVPP precipitation, fractions 7-11 of $E$. nuttallii and fractions 7-10 of $E$. canadensis stimulated growth significantly compared to PVPP controls. Compared to not PVPP treated fractions, fractions 811 of both Elodea species exhibited significant differences (Fig. 3C, G). S. nidulans was neither inhibited nor stimulated by any original or PVPP treated fraction. Only PVPP precipitation of the crude extract of $E$. canadensis significantly reduced the inhibitory effect (Fig. 3H).

Similarly, precipitation of phenolic compounds by PVPP did not affect or slightly reduced the allelopathic activity of $E$. nuttallii (campus pond) crude extracts against Anabaena PCC 7120 in the ADA $(7.6 \pm 0.6 \mathrm{~mm}$ versus $3.4 \pm 3.2 \mathrm{~mm}$ and $10.4 \pm 1.1 \mathrm{~mm}$ versus $9.2 \pm 1.3 \mathrm{~mm}$; untreated versus PVPP treated extracts, 4 and $8 \mathrm{mg} \mathrm{DW}$ ). No inhibition in the ADA was observed for any solvent controls.

\subsection{Effect of Elodea derived flavonoids}

The diglucuronides of luteolin or apigenin and chrysoeriol did not inhibit the growth of Anabaena sp. PCC 7120 and A. variabilis $\mathrm{P} 9$ in the agar diffusion assay when applied as either single fractions or combined in amounts equal to $2 \mathrm{mg}$ DW of Elodea, whereas positive controls (crude extract) caused clearing zones of 7-17.5 (P9) and 14-28 mm (PCC 7120) in diameter. 

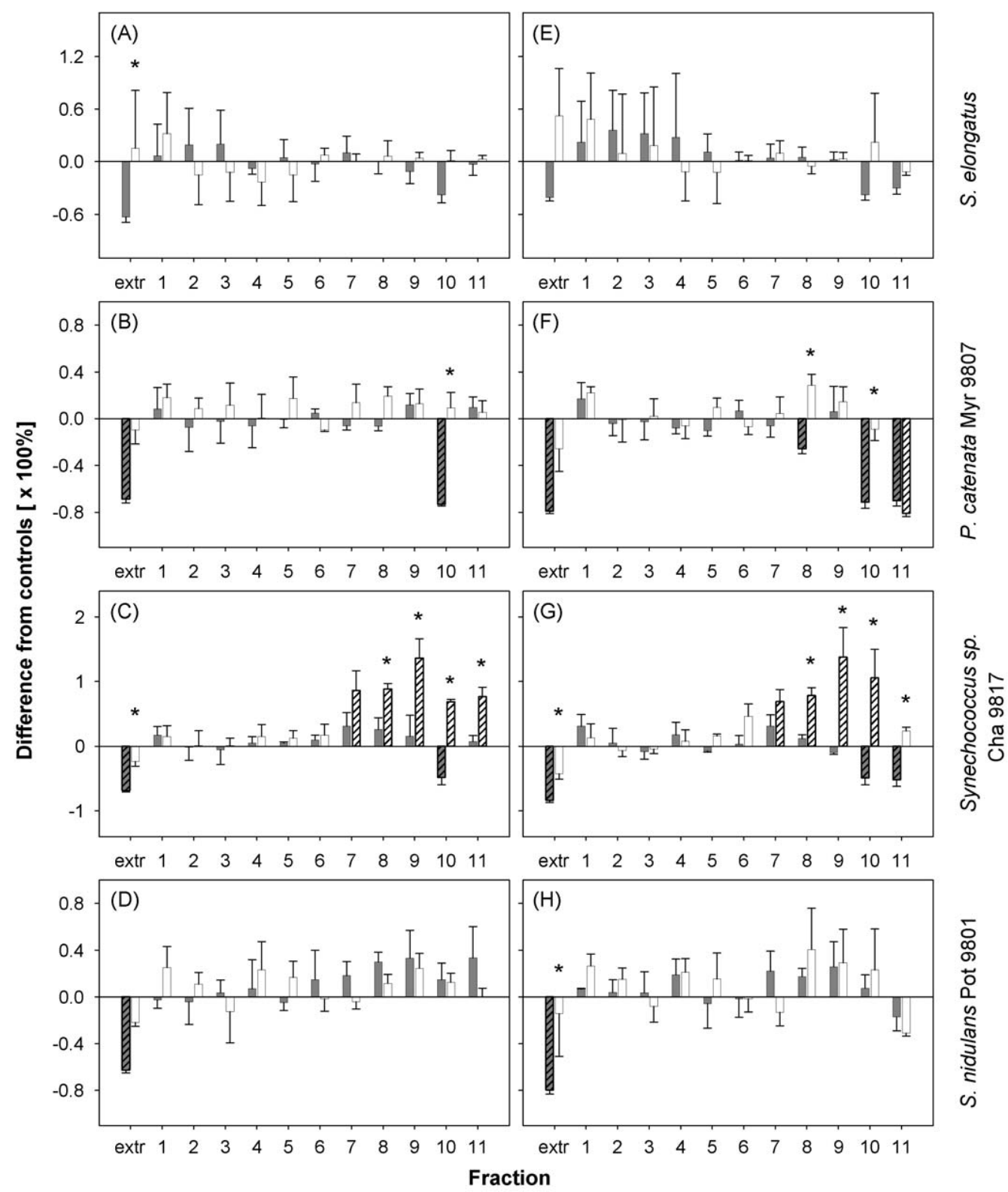

Fig. 3. Growth of S. elongatus, Pseudanabaena Myr 9807, Synechococcus sp. Cha 9817 and S. nidulans Pot 9801 in the presence of crude extracts (extr) and SPE fractions (1-11) equal to $1 \mathrm{mg} \mathrm{DW} \mathrm{ml}{ }^{-1}$ E. nuttallii (A-D) and E. canadensis $(\mathrm{E}-\mathrm{H})$. Given are the differences (mean + S.D., $N=3$ ) from the control cultures. Filled bars represent original extracts (-PVPP), open bars represent extracts precipitated with PVPP to remove phenolic compounds (+PVPP). Hatched bars indicate significant differences to the respective control fractions, asterisks mark significant differences between untreated and PVPP-treated fractions $(P<0.05)$.

\subsection{Exudation of allelochemicals}

Exuded allelochemicals could be trapped from the surrounding medium by solid phase extraction on C18 filters and eluted with methanol. All exudates caused clearing zones in the ADA with Anabaena sp. PCC 7120 when amounts equivalent to ca. $3.5 \mathrm{~g} \mathrm{FW}$ per spot were applied (Fig. 4A). SPE-enriched water from the control did not exhibit clearing zones in the ADA. In two of three tests using different source material, the highest inhibition was observed after $4 \mathrm{~h}$ of incubation, and activity of $24 \mathrm{~h}$ exudates was significantly weaker than that of $2 \mathrm{~h}$ (in experiment 1 ) and $4 \mathrm{~h}$ exudates (in experiments 1 and 3; Tukey HSD, $P<0.05$, following one-way
ANOVA for experiment 1 ; one-sided $t$-test, $P=0.013$ for experiment 3). Diameters of clearing zones in the second exudation experiment did not differ significantly.

Exudates were also tested against $S$. elongatus in the liquid assay, but did not cause significant growth inhibition in concentrations $\leq 150 \mathrm{mg}$ plant FW per milliliter (Fig. 4B). Two and four hour exudates led to a significant decline of $S$. elongatus growth at concentrations of $200 \mathrm{mg} \mathrm{FW} \mathrm{ml}^{-1}(2 \mathrm{~h}$ : $72 \pm 5 \%$ of the controls, Dunnett test, $P=0.03 ; 4$ h: $66 \pm 6 \%$, $P=0.003$ ). Two hour exudates were not tested in the concentration of $150 \mathrm{mg} \mathrm{FW} \mathrm{ml}^{-1}$. Twenty four hours exudates remained inactive at all concentrations tested (83-120\%, $P>0.05)$. 


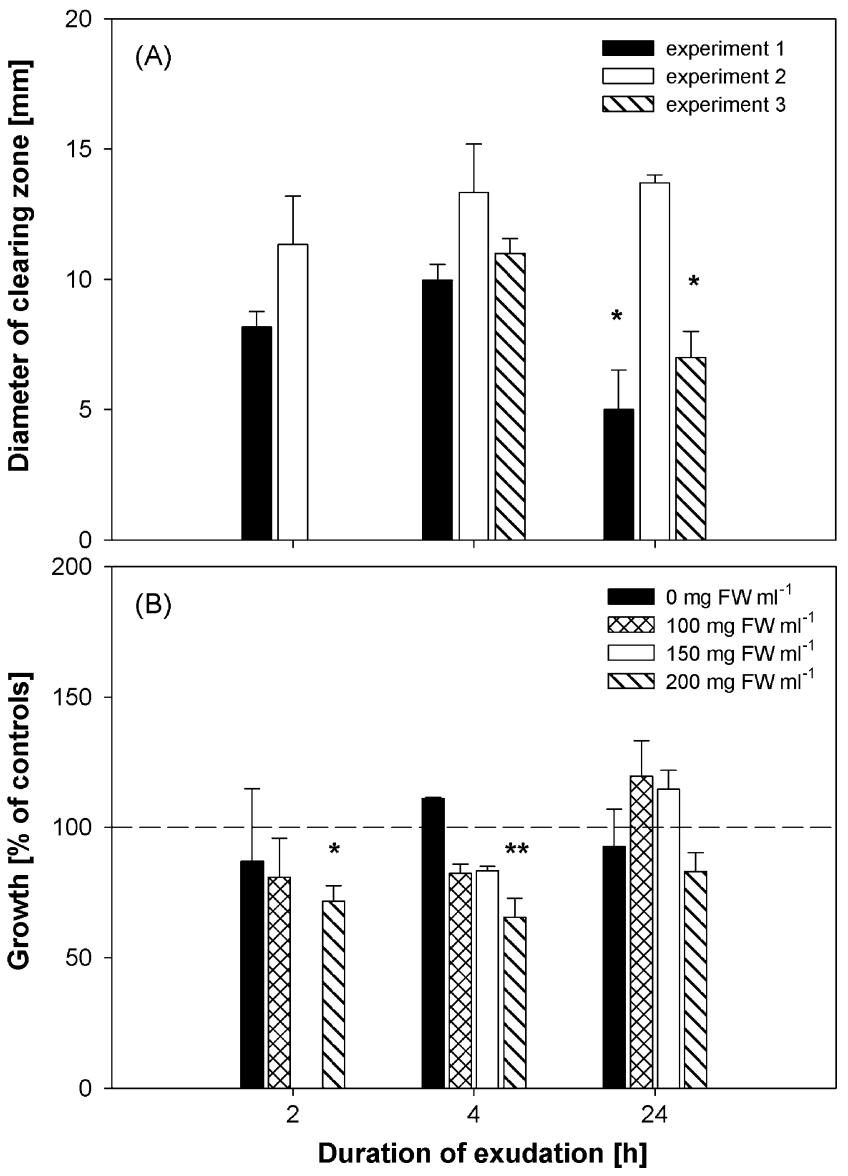

Fig. 4. Effect of E. nuttallii culture filtrate in different bioassays: (A) diameter of clearing zones (mm) in the agar diffusion assay against Anabaena sp. PCC 7120. (B) growth (percentage of controls) of S. elongatus SAG 89.79 in the liquid culture assay. Exudates were sampled after 2, 4 and $24 \mathrm{~h}$ of plant incubation and either applied in $3.5 \mathrm{~g} \mathrm{FW}$ equivalents (A) or in concentrations between 0 and $200 \mathrm{mg} \mathrm{FW} \mathrm{ml}^{-1}$ (B). Given are means + S.D. $(N=3$ per experiment). Asterisks mark exudates with significantly reduced activity (Student's $t$-test or Dunnett test, significance levels ${ }^{*} P<0.05$ and ${ }^{* *} P<0.01$ ).

\section{Discussion}

We showed that extracts from two Elodea species, E. canadensis and E. nuttallii, and exudates of E. nuttallii reduce the growth of several aquatic primary producers, among them epiphytic algae and cyanobacteria isolated from different submersed macrophytes. Our results expand the so far scarce studies on allelopathy of Elodea towards ecologically relevant target organisms. Low epiphyte densities on Elodea were frequently reported (Wium-Andersen, 1987; Jones et al., 1999; Gross et al., 2003b), and allelopathy might be one mechanism to account for this.

Our separations of Elodea extracts showed that the active compounds are hydrophilic and moderately lipophilic. SPE further resolved up to three active fractions in the extracts. However, the polar fraction 1 did only exhibit allelopathic activity in the ADA, whereas the moderately lipophilic fractions 10 and/or 11 were inhibitory in both assays against various target organisms. In most cases, the extent of growth reduction of these two fractions resembled that of crude extracts alone. Since all separations were made with the same plant material, the inconsistent activity of the compounds in fraction 1 could result from concentrations near to the threshold concentration needed to cause an effect or different chemical stability of hydrophilic compounds on agar or in liquid medium. Aqueous Elodea extracts were also active in the experiments of El-Ghazal and Riemer (1986), and polar active fractions have been found in extracts of Najas marina and Ceratophyllum demersum (Gross et al., 2003a). Such compounds might be exuded into the surrounding water. The substance in fraction 10 of both E. canadensis and E. nuttallii is most probably a phenolic compound, and also at least one of the compounds in fraction 11 of E. canadensis appears to be of phenolic nature. Since the indicator strains responded differently to this fraction after PVPP addition, we assume that there might be more, mainly non-phenolic compounds with inhibitory activity present. Although not supported by SPE fractionation, this should also be true for $E$. nuttallii because crude extracts remained active against Anabaena sp. PCC 7120 after PVPP addition. This could be a result of threshold concentrations, but also synergistic or additive effects might have caused a stronger activity in the precipitated crude extracts compared to the single fractions.

Among the phenolic allelochemicals isolated so far from freshwater primary producers are simple phenolic acids as well as complex hydrolysable tannins (summarised in Gross, 1999, 2003). Gallo- or ellagitannins such as tellimagrandin II from $M$. spicatum (Gross et al., 1996) are not synthesised by monocotyledons (Haslam and Lilley, 1986). Elodea species contain diglucuronides of the flavones luteolin, apigenin and chrysoeriol and a yet unidentified phenolic acid similar to caffeic acid (Mues, 1983; Erhard and Gross, 2005). Various flavonoids have been demonstrated to inhibit growth of gram negative bacteria (Basile et al., 1999), to which also cyanobacteria belong (Schlegel, 1992), but purified Elodea flavonoids did not exhibit allelopathic activity in the ADA. Thus, we can exclude them as directly active allelochemicals. However, we did not test the respective aglycones. Bacterial metabolism could produce aglycones in nature, whereas our ADA was performed under axenic conditions. At present, it is unclear which (secondary) compounds are responsible for the allelopathic activity in Elodea.

Despite a differential inhibitory effect of SPE fractions from both Elodea species, the activity of crude extracts did not differ when tested against the same target organism. This indicates that several active fractions add up to the allelopathic activity. However, effects varied depending on the indicator organism used in the assay. Such variations have also been observed by other authors (Aliotta et al., 1990; Aliotta et al., 1991; Gross et al., 2003a), and the different susceptibility to Elodea allelochemicals might be a result of host specificity and adaptation to plant metabolites. Strikingly, the commercially available culture cyanobacteria were most strongly inhibited by Elodea extracts. These cultures are not epiphytic and should not be adapted to any plant metabolites. They are thus suitable target organisms to detect active compounds, and culture strains of cyanobacteria are in fact often used in allelopathy assays 
(e.g., Aliotta et al., 1990; Gross et al., 1996; Nakai et al., 1996; Gross et al., 2003a). The response of the epiphyte isolates was more differentiated. Cyanobacteria showed inhibition patterns towards crude extracts similar to S. elongatus, whereas Chlorella cf. vulgaris Elo 5B was less sensitive and growth of S. brevispina Naj S52 was even increased. This indicates that S. brevispina might profit from growth stimulating compounds more than it suffered from allelochemicals. Chlorella $\mathrm{cf}$. vulgaris isolated from Elodea seems partly adapted to its host plant. Scenedesmus, although isolated from Najas, is ubiquitous in epiphytic biofilms and can reach high abundances on aquatic macrophytes (Eminson and Moss, 1980). As stated in the methods section, we used a silica-free medium to isolate epiphytic species and thus selected for green algae and cyanobacteria and missed out diatoms. Species composition of epiphytes depends on both season and site (Eminson and Moss, 1980; Müller, 1994), but epiphytic algal communities are usually dominated by diatoms (Sand-Jensen and Søndergaard, 1981; Blindow, 1987; Müller, 1994; Cattaneo et al., 1998; Müller, 1999; James et al., 2000). Especially Cocconeis sp. or Gomphonema are frequently found on Elodea (Erhard, personal observation). Green algae can reach high densities in spring or summer, and cyanobacteria never reach high densities (Eminson and Moss, 1980; Müller, 1994; Roberts et al., 2003). We thus hypothesise that the epiphytic organisms we investigated play a minor role as epiphytes on Elodea, also because of the allelopathic activity towards them. Several studies indicate that cyanobacteria are especially susceptible to allelopathy (Aliotta et al., 1990, 1991; Jasser, 1995; Körner and Nicklisch, 2002).

An important, yet often ignored requirement for the ecological relevance of potential allelochemicals is their release by the plants (Willis, 1985). Only few aquatic macrophytes have been demonstrated to exude active compounds, e.g., Myriophyllum spicatum, Najas marina, Ceratophyllum demersum and Stratiotes aloides (Gross et al., 1996; Nakai et al., 2000; Körner and Nicklisch, 2002; Gross et al., 2003a; Mulderij et al., 2005). For Chara or Sium erectum, a release could not be shown (WiumAndersen et al., 1982; Wium-Andersen et al., 1987). Our experiments show that inhibitory substances can be extracted from the surrounding water of Elodea. However, the amounts of exudates needed to cause significant growth reductions was much higher than of crude extracts or fractions. We nevertheless suggest that concentrations used in our experiments reflect ecologically realistic concentrations. E. canadensis and E. nuttallii reach high biomass of 500-1693 $\mathrm{g} \mathrm{DW} \mathrm{m}^{-2}$, respectively (Pokorny et al., 1984; Cook and Urmi-König, 1985) with most of this biomass located at the water surface. Epiphytic organisms further live in closer contact to the plants and consequently, allelochemicals need not to be transported over a long distance. Allelochemicals should reach higher concentrations in the boundary layer of leaves. Sher-Kaul et al. (1995) calculated the leaf area of E. canadensis to $1255 \mathrm{~cm}^{2} \mathrm{~g}^{-1} \mathrm{DW}$. In a distance of $1 \mathrm{~mm}, 1 \mathrm{~g}$ DW Elodea would be surrounded by $125.5 \mathrm{ml}$, which equals $7.97 \mathrm{mg} \mathrm{DW} \mathrm{ml}^{-1}$ or ca. $96 \mathrm{mg}$ $\mathrm{FW} \mathrm{ml}^{-1}$. This is about half of the effective concentration in our bioassays with exudates. We did not examine exudation rates nor did we test the chronic exposure of target organisms to plant allelochemicals. Sublethal effects might occur during long-term exposure while during short-time exposure the same concentrations might still be inactive. We assume a constant exudation of low concentrations of active compounds by Elodea under natural conditions, and this should decrease the concentrations needed to exhibit deleterious effects. Constant exudation is also important to compensate for dilution or natural degradation. The latter seemed to be relevant in our exudation experiments as indicated by the inhibition pattern over time. From the lower activity in 24 h exudates we conclude that exuded Elodea allelochemicals were either labile or metabolised by bacteria, as observed with Myriophyllum exudates (Nakai et al., 2000). Axenic cultures of Elodea would be desirable to investigate the influence of bacterial metabolism on the effect of plant derived compounds. So far, no axenic culture of Elodea could be established.

Together with traits such as high growth and photosynthetic rates under a broad range of chemical and physical parameters, or adaptation to low light intensities (Jahnke et al., 1991; Dendène et al., 1993; Jones et al., 1993; Ozimek et al., 1993), allelopathic interference with algae and cyanobacteria might allow Elodea to become invasive. Whether also direct allelopathic effects towards macrophytes at least partially account for the displacement of native species, is not clear. Such interactions are known from terrestrial invasive plants (Bais et al., 2003) and have been found between Myriophyllum and other submersed aquatics (Agami and Waisel, 1985), but have never been examined for Elodea. Further studies are needed to determine the role of allelopathy in the interaction with other primary producers for the success and competitiveness of this aquatic invader.

\section{Acknowledgements}

The help of Julia Buiculescu, Rene Gergs, Ruben Gutzat, Sandra Lutz, Kathrin Nühse and Sonja Wicks in the bioassays is gratefully acknowledged. Kirsten König and Reiner Kümmerlin from the Institute for Lake Research, Langenargen, Germany, deserve special recognition for their help in determining the epiphyte species. Jan Vermaat and two anonymous reviewers made valuable comments on the manuscript. This study was supported by the German Science Foundation (SFB 454, project A2 to EMG) and the University of Konstanz (AFF).

\section{References}

Agami, M., Waisel, Y., 1985. Inter-relationship between Najas marina L. and three other species of aquatic macrophytes. Hydrobiologia 126, 169-173.

Aliotta, G., Della Greca, M., Monaco, P., Pinto, G., Pollio, A., Previtera, L., 1990. In vitro algal growth inhibition by phytotoxins of Typha latifolia L. J. Chem. Ecol. 16, 2637-2646.

Aliotta, G., Monaco, P., Pinto, G., Pollio, A., Previtera, L., 1991. Potential allelochemicals from Pistia stratiotes L. J. Chem. Ecol. 17, 2223-2234.

Bais, H.P., Vepachedu, R., Gilroy, S., Callaway, R.M., Vivanco, J.M., 2003. Allelopathy and exotic plant invasions: from molecules and genes to species interactions. Science 301, 1377-1380.

Barrat-Segretain, M.-H., 2001. Invasive species in the Rhone River floodplain (France): replacement of Elodea canadensis Michaux by E. nuttallii St. John in two former river channels. Arch. Hydrob. 152, 237-251. 
Basile, A., Giordano, S., Lopez-Saez Jose, A., Castaldo Cobianchi, R., 1999. Antibacterial activity of pure flavonoids isolated from mosses. Phytochemistry $52,1479-1482$.

Blindow, I., 1987. The composition and density of epiphyton on several species of submerged macrophytes - the neutral substrate hypothesis tested. Aquat. Bot. 29, 157-168.

Cattaneo, A., Galanti, G., Gentinetta, S., Romo, S., 1998. Epiphytic algae and macroinvertebrates on submerged and floating-leaved macrophytes in an Italian lake. Freshw. Biol. 39, 725-740.

Cook, C.D.K., Urmi-König, K., 1985. A revision of the genus Elodea (Hydrocharitaceae). Aquat. Bot. 21, 111-156.

Dendène, M.A., Rolland, T., Trémolières, M., Carbiener, R., 1993. Effect of ammonium ions on the net photosynthesis of three species of Elodea. Aquat. Bot. 46, 301-315

El-Ghazal, R.A.K., Riemer, D.N., 1986. Germination suppression by extracts of aquatic plants. J. Aquat. Plant Manage. 24, 76-79.

Eminson, D., Moss, B., 1980. The composition and ecology of periphyton communities in freshwaters. I. The influence of host type and external environment on community composition. Br. Phycol. J. 15, 429-446.

Erhard, D., Gross, E.M., 2005. Do environmental factors influence composition of potential allelochemicals in the submersed freshwater macrophyte Elodea nuttallii (Hydrocharitaceae)? Verh. Int. Verein. Limnol. 29, 287-291.

Fitter, A., 2003. Making allelopathy respectable. Science 301, 1337-1338.

Gopal, B., Goel, U., 1993. Competition and allelopathy in aquatic plant communities. Bot. Rev. 59, 155-210.

Gross, E.M., 1999. Allelopathy in benthic and littoral areas: case studies on allelochemicals from benthic cyanobacteria and submersed macrophytes. In: Inderjit, Dakshini, K.M.M., Foy, C.L. (Eds.), Principles and Practices in Plant Ecology: Allelochemical Interactions. CRC Press, LLC, pp. 179-199.

Gross, E.M., 2003. Allelopathy of aquatic autotrophs. Crit. Rev. Plant Sci. 22, 313-339.

Gross, E.M., Meyer, H., Schilling, G., 1996. Release and ecological impact of algicidal hydrolysable polyphenols in Myriophyllum spicatum. Phytochemistry $41,133-138$

Gross, E.M., Erhard, D., Ivanyi, E., 2003a. Allelopathic activity of Ceratophyllum demersum L. and Najas marina ssp. intermedia (Wolfgang) Casper. Hydrobiologia 506-509, 583-589.

Gross, E.M., Feldbaum, C., Graf, A., 2003b. Epiphyte biomass and elemental composition on submersed macrophytes in shallow eutrophic lakes. Hydrobiologia 506-509, 559-565

Haslam, E., Lilley, T.H., 1986. Polyphenol complexation. In: Farkas, L., Gabor, M., Kallay, F. (Eds.), Flavonoids and Bioflavonoids. Elsevier, Amsterdam, pp. 113-138.

Hasler, A.D., Jones, E., 1949. Demonstration of the antagonistic action of large aquatic plants on algae and rotifers. Ecology 30, 359-364.

Jahnke, L.S., Eighmy, T.T., Fagerberg, W.R., 1991. Studies of Elodea nuttalli grown under photorespiratory conditions I. Photosynthetic characteristics. Plant Cell Environ. 14, 147-156.

James, M.R., Hawes, I., Weatherhead, M., 2000. Removal of settled sediments and periphyton from macrophytes by grazing invertebrates in the littoral zone of a large oligotrophic lake. Freshw. Biol. 44, 311-326.

Jasser, I., 1995. The influence of macrophytes on a phytoplankton community in experimental conditions. Hydrobiologia 306, 21-32.

Jones, J.I., Eaton, J.W., Hardwick, K., 1993. Physiological plasticity in Elodea nuttallii (Planch.) St. John. J. Aquat. Plant Manage. 31, 88-94.

Jones, J.I., Young, J.O., Haynes, G.M., Moss, B., Eaton, J.W., Hardwick, K.J., 1999. Do submerged aquatic plants influence their periphyton to enhance the growth and reproduction of invertebrate mutualists? Oecologia 120, 463-474.

Jupp, B.P., Spence, D.H.N., 1977. Limitations on macrophytes in a eutrophic lake, Loch Leven. I. Effects of phytoplankton. J. Ecol. 65, 175-186.

Jüttner, F., Leonhardt, J., Möhren, S., 1983. Environmental factors affecting the formation of mesityloxid, dimethylallylic alcohol and other volatile compounds excreted by Anabaena cylindrica. J. Gen. Microbiol. 129, 407-412.

Körner, S., Nicklisch, A., 2002. Allelopathic growth inhibition of selected phytoplankton species by submerged macrophytes. J. Phycol. 38, 862-871.

Leu, E., 2001. Wirkung von Allelochemikalien aus submersen Makrophyten auf die Photosynthese. Diploma thsis, University of Freiburg, Freiburg.
Loomis, W.D., Battaile, J., 1966. Plant phenolic compounds and the isolation of plant enzymes. Phytochemistry 5, 423-438.

Madsen, J.D., Hartleb, C.F., Boylen, C.W., 1991. Photosynthetic characteristics of Myriophyllum spicatum and six submersed aquatic macrophyte species native to Lake George, New York. Freshw. Biol. 26, 233-240.

Mues, R., 1983. Species specific flavone glucuronides in Elodea species. Biochem. Syst. Ecol. 11, 261-265.

Mulderij, G., Mooij, W.M., Smolders, A.J.P., Van Donk, E., 2005. Inhibition of phytoplankton by allelopathic substances from Stratiotes aloides. Aquat. Bot. 82, 284-296.

Müller, U., 1994. Seasonal development of epiphytic algae on Phragmites australis (CAV.) TRIN. ex STEN. in a eutrophic lake. Arch. Hydrobiol. 129, 273-292.

Müller, U., 1999. The vertical zonation of adpressed diatoms and other epiphytic algae on Phragmites australis. Eur. J. Phycol. 34, 487-496.

Nakai, S., Hosomi, M., Okada, M., Murakami, A., 1996. Control of algal growth by macrophytes and macrophyte-extracted bioactive compounds. Water Sci. Tech. 34, 227-235.

Nakai, S., Inoue, Y., Hosomi, M., Murakami, A., 2000. Myriophyllum spicatumreleased allelopathic polyphenols inhibiting growth of blue-green algae Microcystis aeruginosa. Water Res. 34, 3026-3032.

Ozimek, T., Van Donk, E., Gulati, R.D., 1993. Growth and nutrient uptake by two species of Elodea in experimental conditions and their role in nutrient accumulation in a macrophyte-dominated lake. Hydrobiologia 251, $13-18$.

Phillips, G.L., Eminson, D., Moss, B., 1978. A mechanism to account for macrophyte decline in progressively eutrophicated freshwaters. Aquat. Bot. 4, 103-126.

Pokorny, J., Kvet, J., Ondok, J.P., Toul, Z., Ostry, I., 1984. Productionecological analysis of a plant community dominated by Elodea canadensis Michx. Aquat. Bot. 19, 263-292.

Roberts, E., Kroker, J., Körner, S., Nicklisch, A., 2003. The role of periphyton during the recolonization of a shallow lake with submerged macrophytes. Hydrobiologia 506-509, 525-530.

Sand-Jensen, K., Søndergaard, M., 1981. Phytoplankton and epiphyte development and their shading effect on submerged macrophytes in lakes of different nutrient status. Int. Rev. Ges. Hydrobio. 66, 529-552.

Schlegel, H.G., 1992. Allgemeine Mikrobiologie, seventh ed. Thieme, Stuttgart.

Schmieder, K., 1998. Submerse Makrophyten der Litoralzone des Bodensees 1993 im Vergleich mit 1978 und 1967. Ber. Int. Gewässerschutzkomm. Bodensee Ber. Nr. 46.

Schrader, K.K., De Regt, M.Q., Tucker, C.S., Duke, S.O., 1997. A rapid bioassay for selective algicides. Weed Technol. 11, 767-774.

Sher-Kaul, S., Oertli, B., Castella, E., Lachavanne, J.-B., 1995. Relationship between biomass and surface area of six submerged aquatic plant species. Aquat. Bot. 51, 147-154.

Thiebaut, G., Rolland, T., Robach, F., Tremolieres, M., Muller, S., 1997. Some consequences of the introduction of two macrophyte species, Elodea canadensis Michaux and Elodea nuttallii St. John, in continental aquatic ecosystems: example of two areas in the North-East of France: alsace Plain and Northern Vosges. B. Fr. Peche Piscic. 0, 441-452.

Tremp, H., 2001. Site specification of the aquatic invasive species Elodea canadensis Michx. and Elodea nuttallii (Planch.) St. John in waters of the right Upper Rhine Floodplain (in German). Ber. Inst. Landschafts-Pflanzenökologie Univ. Hohenheim 10, 19-32.

Vöge, M., 1994. Tauchbeobachtungen in Siedlungsgewässern von Elodea nuttallii (Planch.) St. John. Tuexenia 14, 335-342.

Willis, R.J., 1985. The historical bases of the concept of allelopathy. J. Hist. Biol. 18, 71-102.

Wium-Andersen, S., 1987. Allelopathy among aquatic plants. Arch. Hydrobiol. Beih. Ergebn. Limnol. 27, 167-172.

Wium-Andersen, S., Anthoni, U., Christophersen, C., Houen, G., 1982. Allelopathic effects on phytoplankton by substances isolated from aquatic macrophytes (Charales). Oikos 39, 187-190.

Wium-Andersen, S., Jorgensen, K.H., Christophersen, C., Anthoni, U., 1987. Algal growth inhibitors in Sium erectum HUDS. Arch. Hydrobiol. 111, $317-320$. 